\title{
The St. Louis Equation: A Decade Later
}

\author{
TERRY G. SEAKS
}

The University of North Carolina at Greensboro

STUART D. ALLEN

The University of North Carolina at Greensboro

\section{Introduction}

Ever since the publication of the "St. Louis Equation" by Andersen and Jorden [2] and its later appearance as a cornerstone of the St. Louis Model [1], the equation has been the subject of great debate. The equation showed that quarterly changes in the money stock exerted a much greater influence on nominal GNP than did quarterly changes in high employment federal spending. Predictably, the equation provoked a number of counter studies which investigated problems with data definitions, reduced-form equations, time periods studied, and the Almon specification of the regression model.

A decade has now elapsed since the original equation appeared in 1968 and it became part of a monetarist model in 1970 . The aim of the present investigation is to see how well the original equation stands up to a variety of econometric tests when the data from the ensuing decade are added to the original sample period. Our goal is not to consider all of the problems mentioned above, but rather to test the equation on its own ground.

The original St. Louis equation and an updated version are presented in Section II. The results of both sample periods are compared and subjected to the standard Chow test for structural stability. The tendency of some of the coefficients to "drift" over time is explored. In Section III the question of the lag length and endpoint constraints that are imposed during the Almon lag estimation are considered. In Section IV we consider a Box-Cox analysis of the functional form of the equation, and in a closing section we summarize our results.

\section{The St. Louis Equation: Then and Now}

The St. Louis equation relates changes in nominal GNP $(\Delta Y)$ to changes in the narrowly defined money stock $(\Delta M)$ and changes in high employment federal spending $(\Delta E)$. The equation to be estimated is:

$$
\Delta Y_{t}=a+\sum_{t=0}^{4} m_{i} \Delta M_{t-i}+\sum_{i=0}^{4} e_{i} \Delta E_{t-i}
$$


Table I shows the estimates of the original equation used by Andersen and Carlson in the St. Louis Model which was estimated with quarterly data from 1953/I to 1969/IV. The coefficients are estimated with the Almon lag technique and are required to lie along a fourth degree polynomial with both endpoints restricted to be zero. For comparison with some later results, Table I also shows the equation when percentage growth rates of the variables are employed instead of first differences. We refer to the two versions of the equation as the $\Delta Y$ and the $\dot{Y}$ version.

The original $\Delta Y$ version of the equation shows that the impact of $\Delta M$ peaks after the first quarter and gradually trails off to approximately zero after four quarters. The $t$ values associated with the coefficients on the money terms are uniformly significant except for the fourth quarter. Further, the sum of the coefficients is 5.23 , indicating a five-fold multiplier associated with changes in the money stock. In contrast, the coefficients for the expenditure terms are much smaller. The coefficients change sign and magnitude in such a way that changes in expenditures are self-canceling after a period of time. The sum of the expenditure coefficients is essentially zero (.07) and insignificant in terms of its $t$ value (.22). The equation obviously does fairly well, since it manages to explain almost $70 \%$ of the quarterly changes in GNP.

The updated $\Delta Y$ version also reported in Table I exhibits considerable change in the distribution of the $\Delta M$ coefficients. While the $\Delta M$ coefficients previously rose to a peak and declined, they now decline gradually in strength from period 0 to period 3 and then rise slightly in the last period. Whereas four of the five $\Delta M$ coefficients were statistically significant in the original version, only two of the five coefficients are significant in the updated version. Even more striking than the change in the $\Delta M$ coefficients is the change in the $\Delta E$ coefficients. While the $\Delta E$ coefficients previously oscillated in sign and summed to a value which was not significantly different from zero, now all of the $\Delta E$ coefficients are positive, and three are statistically signficant. Further, the sum of the expenditure coefficients is 1.54 with a $t$ statistic of 4.38 . The increase in the size and the significance of the $\Delta E$ coefficients led Benjamin Friedman [6] to conclude that the St. Louis equation now does believe in fiscal policy.'

However, Carlson [5] has pointed out the results of updating the $\Delta Y$ version of the equation may be misleading due to the presence of heteroskedasticity. In applying the Goldfeld-Quandt test for heteroskedasticity to the $\Delta Y$ version when updated through 1976/IV, Carlson found strong evidence of heteroskedasticity and easily rejected the hypothesis of stable error variance. Our sample periods confirm what Carlson found. The original sample period gave a standard error of 3.99, while the updated version gives a standard error of 8.04. Since heteroskedasticity results in incorrect coefficient standard errors and $t$ values, the statistical significance of the sum of the $\Delta E$ coefficients cannot be relied upon.

Because of the problem with heteroskedasticity, Carlson suggests that the appropriate specification of the model is in percentage form which passes the Goldfeld-Quandt test for heteroskedasticity. ${ }^{2}$ The absence of a significant problem with heteroskedasticity in the $\dot{Y}$ version is apparent from the standard errors of the regression found in Table I. The standard of 4.3 .

1. Friedman's updated version was for the $1953 / \mathrm{I}$ to $1976 / \mathrm{II}$ period. The sum of $\Delta E$ was 1.42 with a $t$ statistic

2. The idea of estimating the equation in percentage form was discussed in a footnote in the original Anderson-Jordan presentation, but then discarded because the first difference form produced the more interesting multipliers. 


\section{$\Delta \mathrm{Y}$ Version}

$\underline{\text { LAG }}$

0

$\begin{array}{ll}1 \\ & \\ & \\ & \\ & \\ & \\ & \\ & \end{array}$

$\begin{array}{lc}\frac{\Delta \mathrm{M}}{1.23} & \underline{\Delta \mathrm{E}} \\ (2.81) * * & (2.38) * \\ 1.91 & .53 \\ (7.61) * * & (4.11) * * \\ 1.62 & .15 \\ (4.14) * * & (.84) \\ .67 & -.40 \\ (2.75) * * & (-3.07) * * \\ -.26 & -.68 \\ (-.56) & (-3.25) * *\end{array}$

$5.23 \quad .07$

$(7.98) * *$

(.22)

2.35

970.674

.69

68

3.99

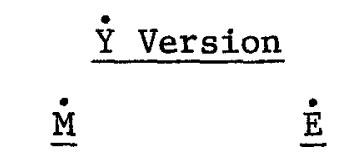

$$
\begin{aligned}
& .29 \\
& (1.99) * \quad(1.76)
\end{aligned}
$$

$$
\begin{gathered}
.46 \\
(5.84) * *
\end{gathered}
$$

.09

$(3.68) * *$

$\begin{array}{cc}.38 & .03 \\ (3.08) * * & (.75)\end{array}$
.10
(1. 28)
$-.09$
$(-3.68) * *$

$-.16$

$(-1.09)$

$-.16$

$(-4.07) * *$

$$
1.08
$$

$-.06$

$(4.88) * *$

$(-.89)$

3.23

649.623

.53

68

3.26
$\Delta \mathrm{Y}$ Version

\section{$\Delta \mathrm{M}$}

$\underline{\Delta E}$

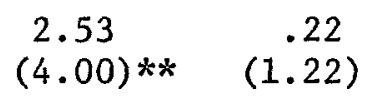

1.83

$(4.91) * *$

$$
.56
$$

(.97)

$$
.35
$$$$
(2.20) *
$$

.05

$$
.37
$$$$
\text { (2. 58)** }
$$

.31

.30

$(.48)$

(1. 52)

5.28

$(6.50) * *$

1.54

$-.02$

(4. 38$) * *$

6008.20

.73

100

8.04
$(2.31$

\section{$\underline{\dot{Y}}$ Version}

$\underline{\dot{M}} \quad \underline{\dot{E}}$

\section{.38}

$(2.77) * *$

.08

$(2.10) *$

$$
(5.48) * *
$$

$(2.53) *$

.27
$(2.22) *$

.01

.06

(.70)

$-.05$

$(-2.16) *$

$-.08$

$-.07$

$(-.58) \quad(-2.01) *$

Significant at .05 level, two tail. "Significant at .01 level, two tail. 
errors are 3.26 for the original sample period and 3.72 for the updated period. The increase in the standard error is 14 percent as compared with more than a 100 percent increase in the standard error in the updated $\Delta Y$ version.

The $\dot{Y}$ version produces similar results for both sample periods-a reassuring finding. The $\dot{M}$ coefficients appear to be "well-behaved" in the sense of rising to a peak in the first lagged period and tapering off to approximately zero. The sum of the monetary coefficients is very close to unity with a $t$-value of around five. The sum of the $\dot{E}$ coefficients is almost exactly equal to zero and the coefficients are statistically insignificant for both sample periods. The constant term is approximately three which implies a tendency for GNP to grow about 3 percent a year without monetary or fiscal stimulus. The value agrees reasonably well with the long-run real growth of the economy.

When the original $\Delta Y$ equation was presented by Andersen and Jordan, the sample period was divided in half and the model was subjected to the Chow test for structural stability. According to the authors $[2,16]$, the hypothesis of no structural change could not be rejected. Carlson has presented a more up-to-date version of the model, but curiously neglects to apply the routine Chow test. Neither the $\Delta Y$ nor the $\dot{Y}$ versions of the equation exhibits parameter stability, but the $\dot{Y}$ version comes closer to being stable. The appropriate test statistics for testing the structural stability of the models are $F_{7,86}=5.08$ and 3.53 for the $\Delta Y$ and $\dot{Y}$ versions respectively. ${ }^{3}$ The critical values of $F_{7,86}$ are 2.11 and 2.86 for 5 percent and 1 percent tests respectively, so the hypothesis of structural stability is easily rejected at conventional test levels.

Although Carlson does not present results of the usual Chow test, he does make reference to a somewhat similar type of analysis due to Brown, Durbin, and Evans [4]. As these authors describe their test, they say [4, 149-50]: "Essentially, the techniques are designed to bring out departures from constancy of regression coefficients in a graphic way instead of parameterizing particular types of departure in advance and then developing formal significance tests intended to have high power against these particular alternatives." Thus, their methods tend to be more judgmental and do not lend themselves very well to tests of hypothesis. Carlson's report that the $\dot{Y}$ version of the equation appears to be stable while the $\Delta Y$ version does not is then open to some question as to exactly how Carlson conducted his test. No information is given in his article.

One of the methods for testing the constancy of a regression that is discussed by Brown, Durbin, and Evans involves examining what they term "moving regressions" [4, 155]. They suggest that a useful way of investigating the time-variation of the coefficient vector is to fit the regression equation for different segments of time and plot the resulting coefficients, thus obtaining a visual impression of stability. In Table II we present results of estimating the St. Louis equation when successive four quarter increments (a full calendar year) are added to the original equation. Although Brown, Durbin, and Evans suggest actually "moving" the regression by dropping the oldest observations as new data are available, we have not dropped the oldest observations in order to maximize degrees of freedom.

3. When estimating for the period $1970 / \mathrm{I}$ to $1977 / \mathrm{IV}$, the $\Delta Y$ and $\dot{Y}$ versions give sum of squared errors of 3279.90 and 347.742 respectively. Using the other sums of squares from Table I, the test statistic is easily formed. Note that the $F$ statistic has 7 degrees of freedom in the numerator despite the fact that 11 right hand side coeffcients appear. The Almon lag specification of a fourth degree polynomial with both end-points constrained to zero involves 2 restrictions on the $\dot{M}$ coefficients and 2 restrictions on the $\dot{E}$ coefficients. Note also that the Chow test cannot strictly be applied in the presence of heteroskedasticity, but the procedure is known to be robust. 
Table II Successive Updates of the St. Louis Eauation

\section{$\Delta \mathrm{Y}$ Version}

\begin{tabular}{|c|c|c|c|c|}
\hline Period & $\Sigma \mathrm{m}$ & $\underline{\Sigma e}$ & $\mathbf{R}^{2}$ & $\underline{S E}$ \\
\hline $53 / I-69 / I V$ & 5.23 & .07 & .69 & 3.99 \\
\hline $53 / \mathrm{I}-70 / \mathrm{IV}$ & 5.02 & .00 & .65 & 4.15 \\
\hline $53 / I-71 / I V$ & 4.92 & .19 & .60 & 4.96 \\
\hline $53 / I-72 / I V$ & 5.51 & .27 & .70 & 5.07 \\
\hline $53 / I-73 / I V$ & 6.06 & .39 & .75 & 5.32 \\
\hline $53 / \mathrm{I}-74 / \mathrm{IV}$ & 5.52 & .58 & .74 & 5.51 \\
\hline $53 / I-75 / I V$ & 4.78 & 1.35 & .67 & 7.41 \\
\hline $53 / \mathrm{I}-76 / \mathrm{IV}$ & 4.56 & 1.67 & .69 & 7.63 \\
\hline $53 / I-77 / I V$ & 5.28 & 1.54 & .73 & 8.04 \\
\hline & \multicolumn{4}{|c|}{$\underline{\dot{Y}}$ Version } \\
\hline Period & $\underline{\Sigma m}$ & $\underline{\mathrm{Ee}}$ & $\underline{\mathrm{R}}^{2}$ & $\underline{\mathrm{SE}}$ \\
\hline $53 / I-69 / I V$ & 1.08 & -.06 & .53 & 3.26 \\
\hline $53 / I-70 / I V$ & 1.02 & -.06 & .49 & 3.30 \\
\hline $53 / I-71 / I V$ & .97 & -.05 & .45 & 3.47 \\
\hline $53 / I-72 / I V$ & 1.03 & -.04 & .48 & 3.43 \\
\hline $53 / I-73 / I V$ & 1.11 & -.03 & .47 & 3.47 \\
\hline $53 / I-74 / I V$ & 1.04 & -.03 & .45 & 3.47 \\
\hline $53 / I-75 / I V$ & 1.04 & .01 & .42 & 3.72 \\
\hline $53 / I-76 / I V$ & 1.04 & .03 & .40 & 3.75 \\
\hline $53 / I-77 / I V$ & 1.05 & .02 & .41 & 3.72 \\
\hline
\end{tabular}

In looking at the results in Table II several obvious patterns quickly emerge. Looking at the $\Delta Y$ version, the standard error of the regression (SE) rises steadily from 3.99 to 8.04 and thus shows evidence of the heteroskedasticity which Carlson has reported. The sum of coefficients on the money stock variable is remarkably stable, always being in the neighborhood of five. In contrast the sum of the coefficients on the expenditure variable shows a strong upward trend from about zero to about 1.5 which was the source of Benjamin Friedman's comments [6, 367], "Even the St. Louis model now believes in fiscal policy." 
Turning to the $\dot{Y}$ version of the model, the standard error now shows only a very mild upward trend. The sums of the coefficients on the money and expenditure terms now appear quite stable, with the money coefficients always summing to close to one. There is some tendency for the expenditure coefficients to rise (from -.06 to .02 ), but it is slight.

If Carlson employed a technique similar to the one just outlined, it is not hard to see how the $\Delta Y$ version gives the impression of instability and heteroskedasticity while the $\dot{Y}$ version appears to be a rather stable performer. But as we have noted above, in fact, neither version is stable in terms of the usual $F$ test.

\section{The End Point Restrictions in the Almon Lag Estimation}

One of the better-known articles to discuss the St. Louis equation is due to Schmidt and Waud [8]. They explore several aspects of the equation, but the authors are particularly critical of the fact that the model was estimated using the endpoint restrictions in conjunction with the fourth degree polynomial. Such restrictions on a polynomial lag of length $k$ require that the hypothetical coefficients for periods $t-k-1$ and periods $t+1$ be zero. The result of such endpoint restrictions is to "tie-down" the polynomial at the beginning and end, and thus nudge the shape of the lag distribution toward an inverted $U$ shape. The effect of the endpoint restrictions is shown graphically in Figures 1 and 2 where money coefficients for the $\dot{Y}$ version (full sample period) are shown when the model is estimated with and without endpoint restrictions.

Schmidt and Waud argue that the use of endpoint restrictions is incorrect for two reasons: (1) it may bias coefficient estimates by imposing an incorrect linear restriction on the coefficients, ${ }^{4}(2)$ it may create the impression of a lag where none exists by "smearing" the effect of a variable back through time. To illustrate their point, they took 25 values of real GNP from 52/I to 58/I and regressed these values on themselves with a lag of nine periods and a fourth degree polynomial. If this is done with and without endpoint restrictions, resulting coefficient estimates are: ${ }^{5}$

\begin{tabular}{lllllllll}
$b_{0}$ & $b_{1}$ & $b_{2}$ & $b_{3}$ & $b_{4}$ & $b_{5}$ & $b_{6}$ & $b_{7}$ & $b_{8}$ \\
\hline
\end{tabular}

No endpt.

restrictions

$$
.913
$$

$-.066-.075-.0004$

.053

$.039-.026-.069$

With endpt.

restrictions

$.414 \quad .428$

.249

$$
\begin{array}{lllll}
.035 & -.114 & -.147 & -.068 & .066
\end{array}
$$

4. For a demonstration that the endpoint restrictions in fact involve linear restrictions on the coefficients, see Kmenta [7, 492].

5. The results presented here do not exactly match the example given by Schmidt and Waud, although they are close in most instances. Schmidt and Waud did not make clear in their original article whether they used $52 / \mathrm{I}$ to $58 / I$ for the dependent variable (giving $n=25$ ) or $52 / I$ to $58 / I$ for the independent variables (giving $n=17$ after necessary lagged values are created). Trying both ways, we were not able to replicate their results. Results in the paper use the former approach. One problem concerns the very high collinearity involved. The TSP program was not able to compute the Schmidt-Waud regression. Correspondence with Schmidt established that they used the AUTO ECON program (a double precision program unlike TSP) to do their work. Denis Karnosky of the St. Louis Federal Reserve Bank kindly ran the Schmidt-Waud example on the bank's version of the AUTO ECON program. Presumably, the minor differences are due to data revisions. Given such high collinearity, small changes in the data could easily account for the coefficient differences. 
Obviously the correct result would be a $b_{0}$ value of exactly one. The Almon version without endpoint restrictions comes fairly close, assigning 91 percent of the weight to the current point. However, the endpoint restricted version does indeed smear the lag back in time, and only 41 percent of the weight is assigned to the current period. Schmidt and Waud conclude with the warning $[8,12]$ :

As a result, it seems reasonable to conclude that the above end-point constraints should not be applied unless there is some particular a priori reason (of nature unknown to these authors) to expect them to be true. Certainly they should not be applied as a routine matter.

What Schmidt and Waud do not point out is that the endpoint restrictions can very easily be subjected to a routine $F$ test to find out if in fact they are biasing the coefficients and thus creating the impression of a lag when there may in fact be little or no actual lag. The example which they use provides a very clear example of how this test could prevent a researcher from applying incorrect restrictions.

The sums of squared errors for the two equations above are 7.0356 and 798.4361 for the versions without and with endpoint restrictions. Clearly, the change in the sum of squared errors is dramatic, and it is curious that Schmidt and Waud fail to mention it. The $F$ statistic for testing two endpoint restrictions is $[(798.4361-7.0356) / 2] \div(7.0356 / 20)$ which has 2 and 20 degrees of freedom, or $F_{2,20}=1124.85$. Clearly the null hypothesis of no coefficient bias in the endpoint-restricted version is overwhelmingly rejected. No researcher is likely to fall into the trap that Schmidt and Waud describe if the endpoint restrictions are checked in this way.

We employ the same $F$ test to see if the endpoint restrictions used in the St. Louis equation have resulted in statistically significant coefficient bias and the possible impression of a lag when in fact no lagged relationship exists. Table III presents the $\dot{Y}$ version of the St. Louis equation when it is estimated using a fourth degree polynomial with and without endpoint restrictions.

In terms of the sums of the coefficients on $\dot{M}$ and $\dot{E}$, there is virtually no difference between the constrained and unconstrained versions of the equation. The money coefficients sum to 1.05 in both cases, while the expenditure coefficients sum to .02 and .01 respectively. Where the differences in the two equations arise is in the pattern of the money coefficients, a point made obvious by Figures 1 and 2. The unconstrained coefficients exhibit much more of a "saw-tooth" pattern, while the endpoint restricted coefficients follow a rather smooth inverted $U$.

Using the sums of squares in Table III to compute the appropriate $F$ ratio, we find that $F_{4,89}=(1283.90-1172.69) / 4 \div(1172.69 / 89)=2.11$. (Here we are testing two pairs of endpoint constraints and thus have four degrees of freedom in the numerator.) The critical value of $F_{4,89}$ for a 5 percent test is 2.47 and the corresponding value for a 1 percent test is 3.54 . Thus, at conventional levels, we cannot reject the hypothesis of no coefficient bias due to endpoint restrictions in the Almon lag model. If the corresponding test is performed for the $\Delta Y$ version of the equation, the test statistic is 2.25 and again we cannot reject the null hypothesis.

Thus, the endpoint restrictions incorporated into the original model do not appear to be causing coefficient bias and are not likely to be "smearing" a non-existant lag to create the impression of a lagged relationship. Similar results are obtained if both equations are exam- 
Table III St. Louis Equation With and Without Endpoint Restrictions (Y Version, 53/I-77/IV)

\section{With Endpoint Constraints Without Endpoint Constraints}

\begin{tabular}{|c|c|c|c|c|}
\hline$\underline{\text { LAG }}$ & $\underline{\dot{M}}$ & $\dot{\underline{E}}$ & $\dot{\dot{M}}$ & $\underline{\dot{\mathrm{E}}}$ \\
\hline 0 & $\begin{array}{c}.38 \\
(2.77) * *\end{array}$ & $(2 . .08) *$ & $(3.06) * *$ & $\begin{array}{c}.05 \\
(1.17)\end{array}$ \\
\hline 1 & $\begin{array}{c}.42 \\
(5.48) * *\end{array}$ & $\begin{array}{c}.06 \\
(2.53) *\end{array}$ & $\begin{array}{c}.22 \\
(.91)\end{array}$ & $\begin{array}{c}.10 \\
(2.41) *\end{array}$ \\
\hline 2 & $\begin{array}{c}.27 \\
(2.22) *\end{array}$ & $\begin{array}{c}.01 \\
(.18)\end{array}$ & $\begin{array}{l}.08 \\
(.32)\end{array}$ & $\begin{array}{l}-.02 \\
(-.42)\end{array}$ \\
\hline 3 & $\begin{array}{l}.06 \\
(.70)\end{array}$ & $\begin{array}{l}-.05 \\
(-2.16) *\end{array}$ & $\begin{array}{c}.57 \\
(2.31) *\end{array}$ & $\begin{array}{l}-.02 \\
(-.59)\end{array}$ \\
\hline 4 & $\begin{array}{l}-.08 \\
(-.58)\end{array}$ & $\begin{array}{c}-.07 \\
(-2.01) *\end{array}$ & $\begin{array}{c}-.41 \\
(-2.07) *\end{array}$ & $\begin{array}{c}-.10 \\
(-2.81) * *\end{array}$ \\
\hline SUM & $\begin{array}{l}1.05 \\
(5.62) * *\end{array}$ & $\begin{array}{c}.02 \\
(.30)\end{array}$ & $\begin{array}{l}1.05 \\
(4.09) * *\end{array}$ & $\begin{array}{l}.01 \\
(.11)\end{array}$ \\
\hline CONSTANT & 2.81 & & 2.93 & \\
\hline SSE & 1283.90 & & 1172.69 & \\
\hline $\mathrm{R}^{2}$ & .41 & & .46 & \\
\hline $\mathrm{n}$ & 100 & & 100 & \\
\hline SE & 3.72 & & 3.63 & \\
\hline
\end{tabular}

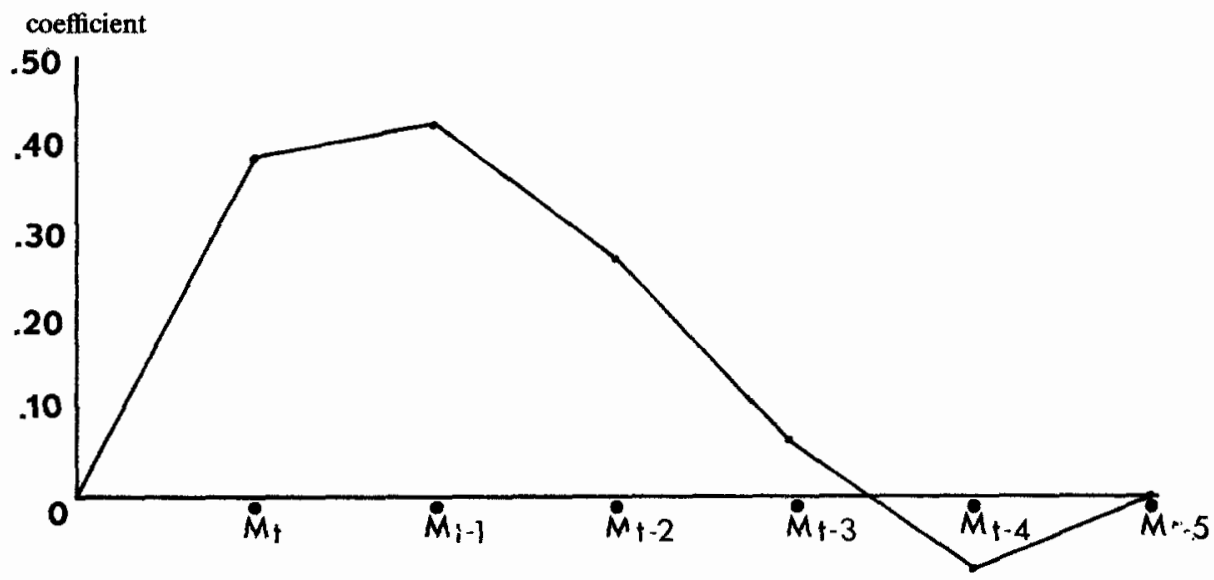

Figure 1. With Endpoint Constraints 
coefficient

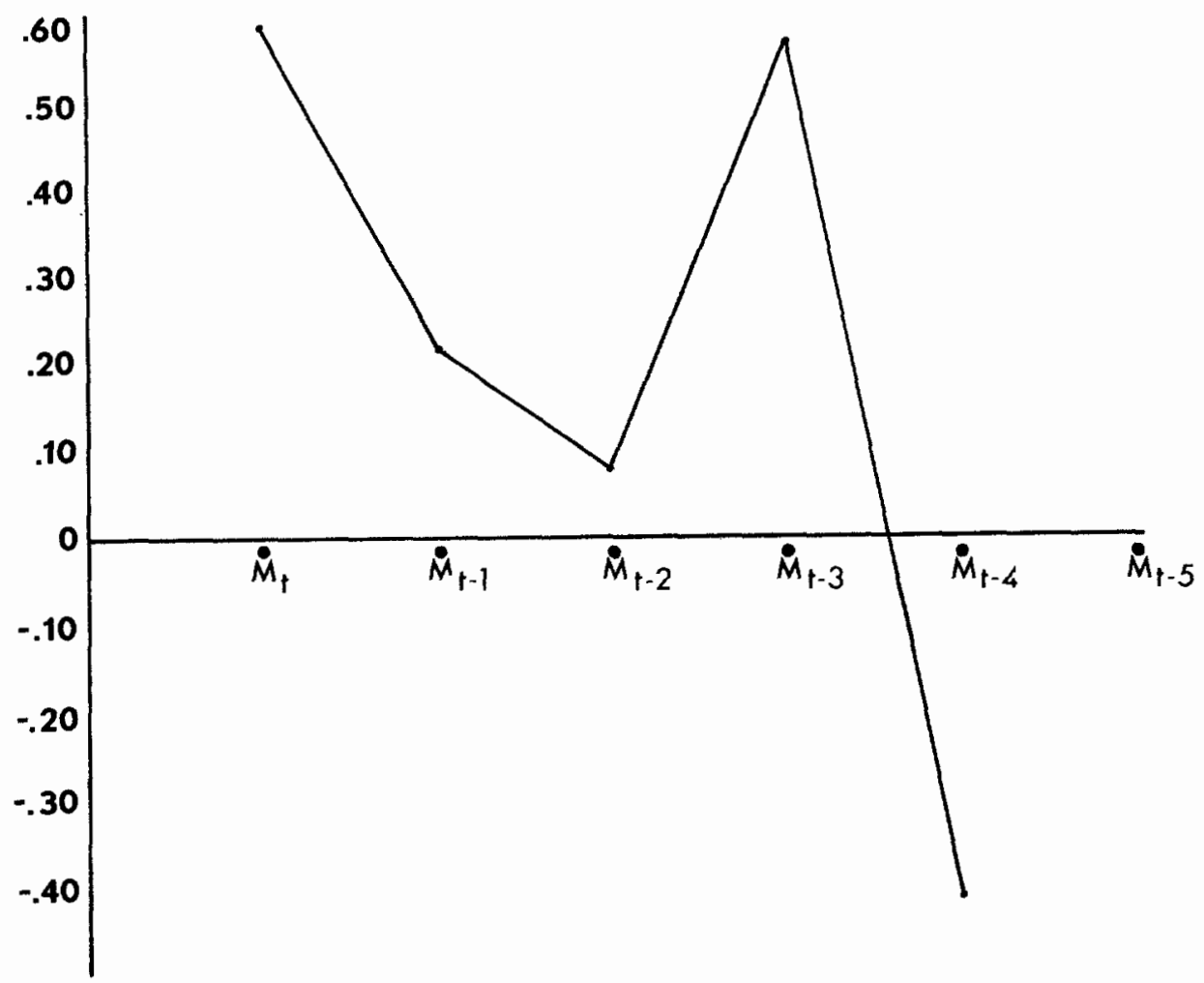

Figure 2. Without Endpoint Constraints

ined over the original time period-a period for which we have more confidence in the coefficients' stability.

\section{Box-Cox Analysis of the Equation}

The St. Louis equation is assumed linear in either the first differences or the percentage changes of the variables. Linear forms have the obvious advantage of simplicity, but one might well ask whether the linear form is in fact consistent with the data. By applying the Box-Cox transformation [3] we can obtain the optimal functional form for the regression equation and investigate whether this optimal form is indeed linear. In practice, the optimal form is not likely to be exactly linear, but we may still ask whether the linear form is in some sense close to optimal.

The Box-Cox analysis of the equation can be carried out by considering the equation:

$$
\left(\dot{Y}_{i}^{\lambda}-1\right) / \lambda=a+\sum_{i=0}^{4} m_{i}\left(\dot{M}_{t-i}^{\lambda}-1\right) / \lambda+\sum_{i=0}^{4} e_{i}\left(\dot{E}_{t-i}^{\lambda}-1\right) / \lambda
$$

where $\dot{Y}, \dot{M}$, and $\dot{E}$ have their previous meanings, $a, m_{i}, e_{i}$, and $\lambda$ are parameters to be estimated, with $\lambda$ the parameter that describes a transformation of the data. If $\lambda=1$, then we 
have simply a linear model which can be estimated by an ordinary regression or Almon procedure. Except for the value of the intercept constant $a$, the results of estimating the equation $\lambda=1$ will be identical to results presented in Table III.

If $\lambda$ is allowed to assume a range of values, the equation then relates various transformations of $\dot{Y}$ to similarly transformed values of $\dot{M}$ and $\dot{E}$. For example, $\lambda=-1$ defines a model in which the reciprocal of $\dot{Y}$ is regressed on reciprocal values of $\dot{M}$ and $\dot{E}$. As $\lambda$ approaches zero, the transformation can be made arbitrarily close to the log function, and the above model becomes a double $\log$ regression. Similarly a value of $\lambda=2$ implies the square of $\dot{Y}$ is regressed on squared values of the right hand side variables.

In applying the Box Cox analysis to the St. Louis equation, we estimate $a$, and $m_{r}$ and $e_{i}$, and $\lambda$ simultaneously by the method of maximum likelihood. Some special purpose programs are available for carrying out this procedure. But the method can also be implemented using the widely available TSP program. The procedure is to have the TSP program scan a range of $\lambda$ values from, say, -2 to +2 by increments of .10 . The value of $\lambda=0$ is replaced by $\lambda=.001$, which closely approximates the double $\log$ model. For each value of $\lambda$ the data are transformed, the regression estimated, and the likelihood function computed. The ML estimates are then obtained by selecting the value of $\lambda$ and associated regression coefficients which correspond to the highest value of the likelihood function.

One slight complication emerges when applying the Box-Cox analysis to the time series data on which the St. Louis equation is based. The difficulty concerns the fact that some values of the variables are negative in some time periods, and the Box-Cox technique requires data values which are strictly positive. For example, the transformation $\left(\dot{Y}^{\lambda}-1\right) / \lambda$ on the left side of equation 2 is not defined for all $\lambda$ from -2 to +2 when $\dot{Y}$ takes on zero or negative values. A $\lambda$ of .5 could require the square root of a negative number.

Several solutions to the problem of negative observations are available. One solution would be to delete negative rows from the observations matrix, but due to the nature of the lagged values in the model this is obviously not attractive. Another solution is to restrict the transformation parameter $\lambda$ to be one for a left or right side variable which is not always positive. Yet another solution is to restrict the sample period to only a time span for which all data values are positive. We have actually employed a combination of the last two alternatives mentioned above.

From $1953 /$ I to $1977 /$ IV there are ten values of $\dot{Y}$ or $\Delta Y$ which are not positive, but all of these values are in the 1950's. If we restrict our attention to the 1961/I to 1977/IV period, all $\dot{Y}$ terms are positive. For this period all but two $\dot{M}$ terms are positive, and the negative values were both very small (less than 1 percent). However, a number of $\dot{E}$ terms were still negative (some approaching - 10.0\%). We have proceeded by replacing the two small negative $\dot{M}$ terms with the average of the actual and two adjacent values, and restricting the value of $\lambda$ to be 1.0 for the $\dot{E}$ terms. ${ }^{6}$ This provides a sample size of 68 , a value equal to the number of observations used in the original St. Louis Model.

When the analysis is carried out on the $\dot{Y}$ and $\Delta Y$ versions of the equation, the results shown in Figures 3 and 4 are obtained. ${ }^{7}$ The figures show the values of $\lambda$ and the correspond1977/IV.

6. The $62 /$ III and 66/III periods contain the only values of $\dot{M}$ which are not strictly positive from $1960 /$ I to

7. The test can be carried out using either the endpoint restricted Almon specification or the version without endpoint restrictions. The latter amounts to OLS, and is what was used. Details on carrying out the Box-Cox analysis using TSP (including a short example) are available from the first author. 


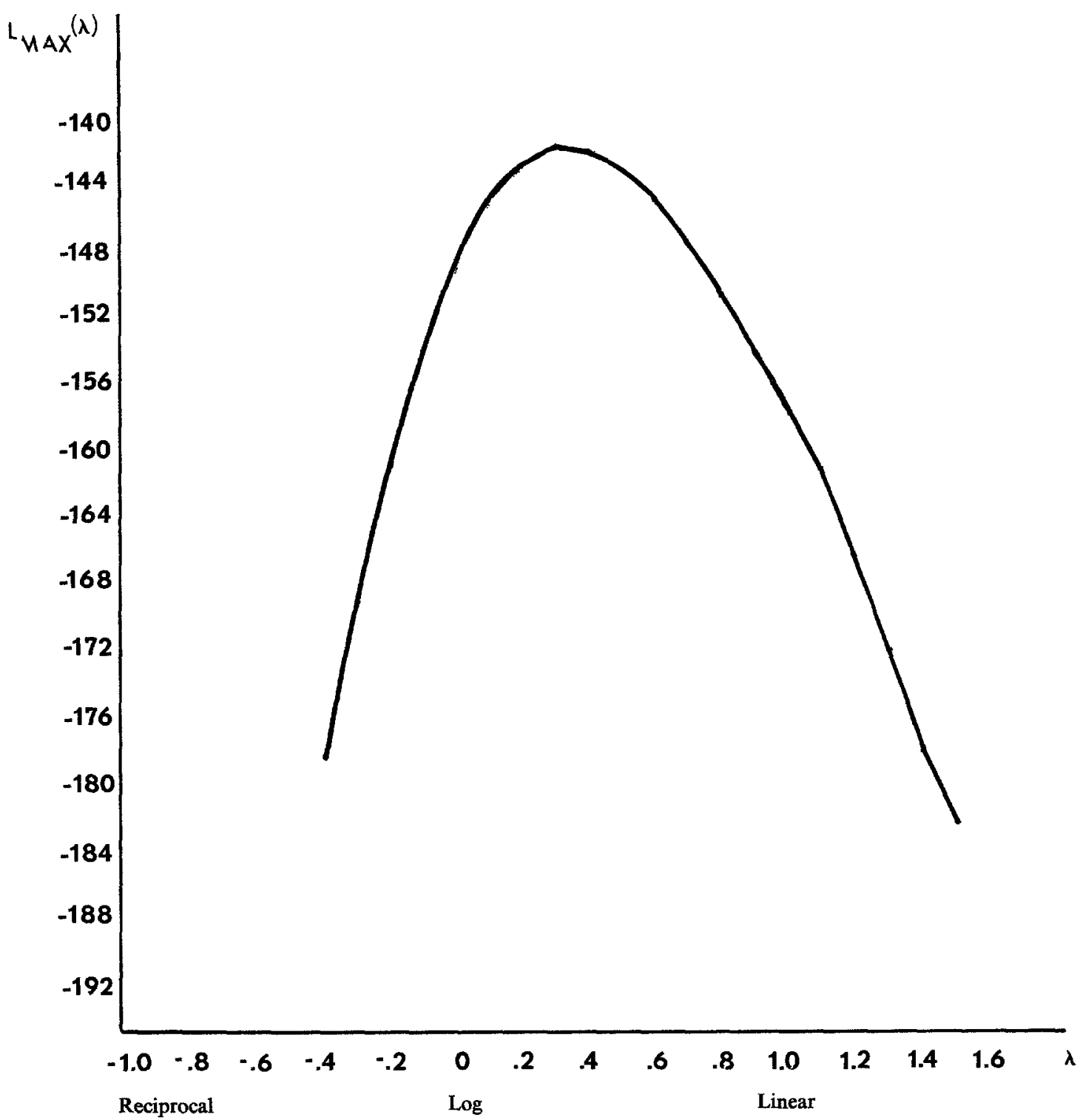

Figure 3. Maximized log-likelihood function for Box-Cox test: $\dot{Y}$ version.

ing $\log$ of the likelihood function. As can be seen from the graphs, the optimal value of the transformation parameter differs considerably between the two versions of the equation. For the first difference version, the estimated value of $\lambda$ is approximately -1.3 , while the percentage change version of the equation yields an estimated $\lambda$ of .3 . The former value corresponds approximately to reciprocal transformation of variables, and the latter value is somewhere between a double log and a linear model.

We may test the hypothesis that $\lambda$ is 1 in each case by employing a likelihood ratio test. By taking twice the difference of the likelihood function at $\lambda=1$ and the likelihood function at the optimal value, we have a test statistic which asymptotically follows a chi-square distri- 


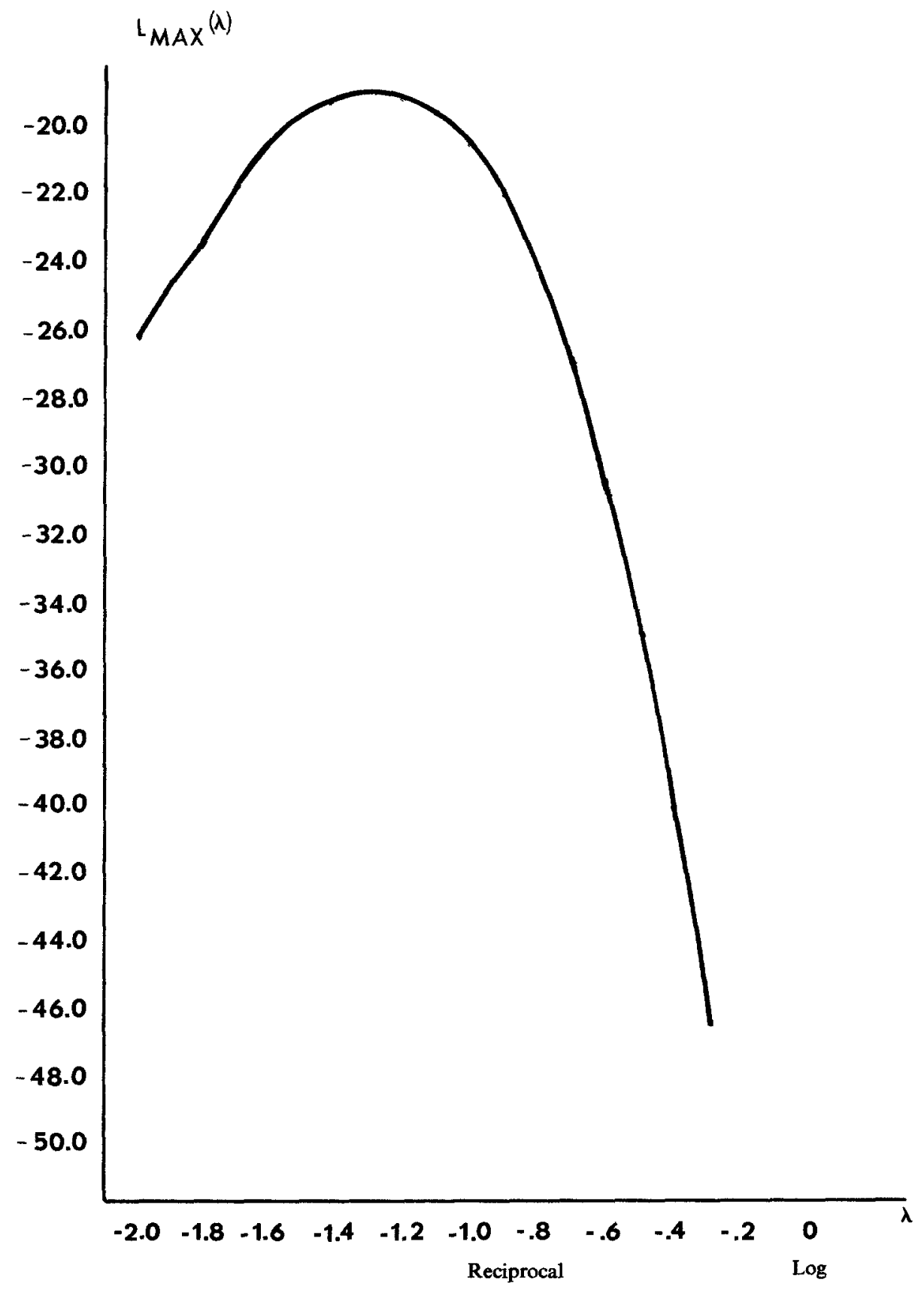

Figure 4. Maximized log likelihood function for Box-Cox test: $\Delta Y$ version.

bution with one degree of freedom. For the $\dot{Y}$ version the test statistic is $2(-141.99+$ $158.29(=32.63$, and the corresponding test statistic for the $\Delta Y$ version gives 207.30.

Both of these values would lead to the rejection of the hypothesis that $\lambda=1$ if testing at any conventional level. The critical value of $\chi_{1}{ }^{2}$ for a 10 percent test is 2.71 , while the corresponding value for a 1 percent test is 6.63. It is interesting, however, that the $\dot{Y}$ version shows 
an optimal value of $\lambda$ that is much closer to 1.0 than does the $\Delta Y$ version of the equation. As we saw earlier, the $\dot{Y}$ version does not have the problems with heteroskedasticity as does the $\Delta Y$ version, and the $\dot{Y}$ specification also comes closer to exhibiting coefficient stability in terms of the Chow test. The Box-Cox analysis has suggested that $\dot{Y}$ is also superior in the sense that it comes closer to fulfilling the linearity assumption imposed during estimation.

\section{Conclusion}

Although an additional decade has increased the sample size fifty percent, a clear verdict on the St. Louis equation still is lacking. Clearly, it does not stand up as well as it could. On some points the equation appears to be suspect. We have shown that it is not structurally stable in either the $\Delta Y$ or $\dot{Y}$ form. Further, the Box-Cox results suggest the equation should not be estimated in its present functional form. It must be admitted, though, that the coefficient stability is not overwhelmingly rejected. Researchers familiar with the Chow test will recognize that few macro models come close to exhibiting parameter stability.

When the Almon specification of the equation is examined, it does not appear inappropriate at conventional significance levels. Further, an examination of the $\sum m$ and $\sum e$ coefficients suggests that the parameter instability is not too great when looked at in terms of successive updates of the model. In either the $\Delta Y$ or $\dot{Y}$ version, the sum of the money coefficients appears rather stable, with most of the change affecting the coefficients on the expenditure terms.

\section{References}

1. Andersen, Leonall C., and Keith M. Carlson, "A Monetarist Model for Economic Stabilization." Review, (Federal Reserve Bank of St. Louis, April 1970), 7-25.

2. Andersen, Leonall C., and Jerry L. Jordan, "Monetary and Fiscal Actions: A Test of Their Relative Importance in Economic Stabilization.” Review, (Federal Reserve Bank of St. Louis, November 1968), 11-24.

3. Box, G. E. P., and D. R. Cox, "An Analysis of Transformation." Journal of the Royal Statistical Society, Series $B$, Vol. 26, 1964, 211-243.

4. Brown, R. L., J. Durbin, and J. M. Evans, "Techniques for Testing the Constancy of Regression Relationships Over Time.” Journal of the Royal Statistical Society, Series B, Vol. 37, 1975, 149-192.

5. Carlson, Keith M., "Does the St. Louis Equation Now Believe in Fiscal Policy?" Review, (Federal Reserve Bank of St. Louis, February 1978), 13-19.

6. Friedman, Benjamin, "Even the St. Louis Model Now Believes in Fiscal Policy." Journal of Money Credit and Banking, May 1977, 365-367.

7. Kmenta, Jan. Elements of Econometrics, McMillan Company, N.Y., 1971.

8. Schmidt, Peter, and Roger N. Waud, "The Almon Lag Technique and the Monetary vs. Fiscal Policy Debate." Journal of the American Statistical Society, March 1973, 11-19. 
Copyright of Southern Economic Journal is the property of Southern Economic Association and its content may not be copied or emailed to multiple sites or posted to a listserv without the copyright holder's express written permission. However, users may print, download, or email articles for individual use. 